\title{
Communication Skills and Its Influence on Teacher Effectiveness
}

\author{
Adeleke Foluso Florence ${ }^{1, *}$, Adesua Veronica Olubunmi ${ }^{1}$, Jimola Folasade Esther ${ }^{2}$ \\ ${ }^{1}$ Department of Educational Management, Ekiti State University, Nigeria \\ ${ }^{2}$ Ekiti State University, Nigeria
}

Received January 19, 2021; Revised October 20, 2021; Accepted November 11, 2021

\begin{abstract}
Cite This Paper in the following Citation Styles
(a): [1] Adeleke Foluso Florence, Adesua Veronica Olubunmi, Jimola Folasade Esther, "Communication Skills and Its Influence on Teacher Effectiveness," Universal Journal of Educational Research, Vol. 10, No. 3, pp. 240 - 245, 2022. DOI: 10.13189/ujer.2022.100306.
\end{abstract}

(b): Adeleke Foluso Florence, Adesua Veronica Olubunmi, Jimola Folasade Esther (2021). Communication Skills and Its Influence on Teacher Effectiveness. Universal Journal of Educational Research, 10(3), 240 - 245. DOI: 10.13189/ujer.2022.100306.

Copyright $\odot 2022$ by authors, all rights reserved. Authors agree that this article remains permanently open access under the terms of the Creative Commons Attribution License 4.0 International License

\begin{abstract}
This study examined the relationship between communication skills and teacher effectiveness in secondary schools in Ekiti State, Nigeria. The study used a survey-type descriptive research design. All teachers and principals of public secondary schools in Ekiti State, Nigeria, were included in the population. The sample for the study was 330 respondents which comprised 300 students and 30 principals selected from 30 secondary schools through simple random sampling technique. The study employed two self-designed questionnaires, the "Communication Skills Questionnaire" (CSQ) and the "Teacher Effectiveness Questionnaire" (TEQ). The instruments were examined for reliability and confirmed by research specialists. The test-retest technique yielded reliability values of 0.78 and 0.73 . Inferential statistics were used to analyse the data collected. The t-test and ANOVA were used to examine the three hypotheses. These hypotheses were evaluated at a significance level of 0.05 . There was a relationship between communication skills and teacher effectiveness in the classroom according to the data. There was a considerable disparity in communication abilities between male and female teachers according to the study. The study further revealed that teachers' teaching experience had no significant influence on communication skills. According to the conclusions of the study, it was advised, among other things, that teachers should continuously enhance their skills of communication in order to improve the teaching-learning processes.
\end{abstract}

Keywords Communication Skills, Teacher
Effectiveness, Teaching Experience, Gender, Teaching-Learning Process

\section{Introduction}

Education is a major determinant that can bring about the development of any nation. The success of an education programme and improvement in education standard depend on the effectiveness of teachers. Teachers translate the aims and objectives of the education into actions in the classroom. The success of any human endeavour is closely related to the quality of skills the person who performs the task demonstrates, hence it could be said that the quality of education is a reflection of her teachers. The art of teaching is defined as a means of transmitting attitude, skills and knowledge in learners so as to cause a desirable and observable change in them. The main goal of teaching is to guarantee that students learn in a meaningful way, desirable and observable change occurs in learners after being exposed to some educational experiences. Observation shows that teachers are the drivers of the goals and objectives of an educational system.

However, observations have indicated deficiencies in the discharge of their duties. Such deficiencies are displayed in their managerial skills, views and attitudes toward learners and learning processes, self-efficacy, subject mastery and assessment techniques, evaluation and 
feedback, inter personal relations, teacher-student relationship, good language, communication skills and teaching methodology which are indices of teacher effectiveness [2]. Teacher effectiveness is seen as multidimensional construct that measures different aspects of teaching such as subject mastery, lesson preparation, lesson presentation, establishing friendly ties with pupils and a teacher's ability to communicate effectively and clarify things. This implies that teacher effectiveness is the extent to which a teacher is ready and dedicated to accomplish teaching objectives. According to [18], the following are four dimensions that are used to define a good teacher: Instructional efficacy, assessment for student learning, a healthy learning environment, and the teacher's personal quality are all factors to consider. An effective teacher is intellectually sound, motivates students, sets high standards and encourages self-initiating learning [4].

Effective classroom communication is very close to what the existing literature refers to as "effective teaching" and it is claimed that effective teachers should possess many different features such as good communication, management and organizational skills [7]. But, the perceived ineffectiveness of some teachers in Nigerian secondary schools seems to be as a result of poor communication skills. Teachers who are unskillful communicators tend to have problems with administrators when making a request. [5] supported that when making a request, teachers who are skilled communicators have a better chance of being heard by administrators. Effective communicators state their request succinctly.

Effective management of students in schools appears to be one of the important key to corporate success. Effective disposition of teaching is supposed to be a panacea to solving individual and group problems alongside the development of the school itself. It is observed that the reverse is the case in some senior secondary schools in Ekiti State, Nigeria as it was observed that there is poor communication gap between the teachers, principal and the students. The consequence of the above paucity usually leads to poor performance and teacher ineffectiveness, of which the aftermath is negative to productivity.

The transmission of a message that involves a shared understanding between the settings in which the conversation takes place is described as communication skill [18]. Communication skills of teachers are crucial in the delivery of education to students. A teacher's ability to communicate effectively is critical in the transmission of education, classroom management, and contact with pupils in the classroom [2]. [20] conducted a study on "Teaching Effectiveness of Secondary School Teachers in the District of Purba Medinipur, West Bengal", There was no significant difference in the level of teaching effectiveness of secondary school teachers based on gender, stream, training status, or qualification, however there was a significant difference based on school location.

[14] in her study "Teachers' effectiveness as correlates of students' academic achievement in Basic Technology in
Nigeria," discovered that Basic Technology teachers' effectiveness was low, which had an impact on students' achievement despite the lack of a significant difference in students' achievement due to teachers' gender. [15] "Teaching efficacy of secondary school teachers in Emohua Local Government Area of Rivers State, Nigeria," according to the study. They found that secondary school instructors in the Emohua Local Government Area had below-average teaching performance. Despite the fact that gender had no substantial impact on secondary school teachers' instructional effectiveness, degree and teaching experience did. [10] researched "Teaching effectiveness of secondary school teachers in relation to their professional commitment". The study showed neither gender of teachers nor locality of schools bore any relationship with their teaching effectiveness. [8] "An assessment of the teaching efficacy of prevocational subject teachers in Ogun State, Nigeria" was the subject of a study. The majority of prevocational subject teachers showed low teaching effectiveness, according to the study's findings.

From the foregoing discussions of the study of related literature, it is obvious that no studies on teacher effectiveness in senior secondary schools in Ekiti State, Nigeria, have been conducted by any researcher. It's also worth noting that none of these studies looked into teachers' communication abilities as a measure of their efficacy. That is why the current researchers chose this title in order to learn about the communication skills of teachers who are employed to instruct pupils in various senior secondary schools in Ekiti State, Nigeria, as well as the impact of communication skills on teacher effectiveness.

Effective management of students in schools appears to be one of the important key to corporate success. Effective disposition of teaching is supposed to be a panacea to solving individual and group problems alongside the development of the school itself. The reverse is the case in schools in Ekiti State as it was observed that there is poor communication gap between the teachers, principal and the students. The consequence of the above paucity usually leads to poor performance and teacher ineffectiveness, of which the aftermath is negative to productivity.

Communication is the transfer of information, messages, thoughts, and ideas which involves a sender, a receiver and a code [3]. Every communication has a purpose. The purpose of all communication is to persuade, influence, modify or change the behavior of others. In education, communication is the information transmitted from a teacher to the pupils, from pupils to the teacher, from pupils to pupils. The teaching learning process itself is a process of communication. Listening and speaking are both important aspects of communication. When the teacher's body language and tone of voice convey openness and encouragement, the student appears to be more receptive. This was supported by [9] that teachers who pay attention to their students' queries and concerns are better able to satisfy their particular requirements and alter their lessons as needed. The transmission of a message that 
involves a shared understanding between the settings in which the conversation takes place is described as communication skill [18].

Communication skills of teachers are crucial in the delivery of education to students. A teacher's ability to communicate effectively is critical in the transmission of education, classroom management, and contact with pupils in the classroom [2]. [17] Effective communication entails selecting the optimal communication channel for a given task, having the technical skills to utilise the channel effectively, presenting information in a way that is appropriate for the target audience, and being able to comprehend messages and responses from others.

The problems and hindrances one experiences or encounters during communication process are referred to as barriers to communication. It appears most teachers encounter problem of meaning. The meaning attached to words and ideas can constitute a problem in communication. At times, teacher expresses something that he/she expects the students to understand but owing to communication gap, problem of semantics and ambiguity, different meanings might be attached or inferred. This could lead to misinterpretation of message and distortion of meaning.

Problem of our thought life could also lead to teacher ineffectiveness. This refers to the way we think about an idea or perceive ideas. Since human being thinks individually and perceives things differently, individual's perception of issues differs. A teacher with good communication skills makes learning subject easier and more understandable for students. The teacher must instruct kids who have diverse ways of thinking. A teacher must adopt communication techniques that urge pupils to engage in their learning process in order to teach according to their aptitude and potential. [3] opined that Teachers' communication skills are critical in the delivery of education, classroom management, and contact with students.

A professional teacher should be aware of the theory and practice in human communication. [6] gave a general conceptual model that underpins this study. This conceptual model attempts to describe and explain communication processes and teachers' effectiveness in school organization. The various components contained in this model are senders, messages, goals, strategies, channels, receivers, outcomes and the context. The context takes the central role in the model because it influences other components in the model. The model further buttresses that the openness of classroom environment and trust level among teachers and students will impact the efficiency and effectiveness of communication [6].

Due to weak communication skills, most teachers were unable to listen carefully to their pupils' questions, according to observations. Communication and interpersonal skills are critical components of the teaching-learning process. The ability of a teacher to communicate effectively with pupils is critical to their academic and professional success. Teachers with inadequate communication skills may contribute to students' failure to learn, eventually affecting their academic performance. Teachers need some essential skills to convey message clearly, effectively and professionally whether verbally or in writing. [2] penned that good teachers' communication skills are essential for students' academic and professional success.

It has been noticed that teachers give pupils more spoken instructions in the classroom. People who are good at communicating are more likely to succeed at employment, especially in the classroom. During the educational process, good communication reduces the possibility of harsh feelings. Students' learning outcomes tend to improve when teachers communicate in a clear and intelligible manner. In the teaching profession, excellent communication is regarded as a valuable tool. [8] believes that effective teaching needs strong communication, classroom management, information upgrading, and personality maintenance. Furthermore, [11] believes that a teacher's capacity to communicate efficiently with students, parents, and coworkers is critical to their performance.

It appears teachers do not communicate effectively while imparting knowledge to students. Teachers' communication skills seem to be faulty when delivering lesson to students. Teacher seems to encounter certain problems and hindrances when transmitting knowledge to students, during the teaching and learning process. This problem might serve as barriers to effective communication. Such barriers may be in form of noise, the meaning attached to words and ideas, misinterpretation of message, while individual students' perception about issues may also differ and could constitute a major problem.

It has been observed that teachers seem to lack communication skills such as listening skills, writing skills, speech skills, conversation skills, discussion skills questioning and answer skills which may invariably affect teacher effectiveness in the school. Communication is more than engaging in just language and inspired activities. It makes use of skills and symbols, hence if the underlying concepts of communication such as interaction, transmission of messages, dissemination, give and take transmitting and receiving are faulty and ineffective, it could hinder teachers effectiveness especially in large classrooms/schools.

It has been observed that factors of sex and working experience may influence teacher effectiveness. For example, female teachers appear to have good communication skills than their male counterparts and this in turn appears to make female teachers effective than their male counterparts in secondary schools. Moreover, it appears that factor of working experience may influence teacher effectiveness. For instance, experienced teachers tend to have good communication skills than less experienced teachers and this in turn appears to make experienced teachers effective than their counterparts with 
less experience.

Thus the effective communication skills of teachers are vital areas to be addressed in any educational system. Therefore, it is necessary to delve into whether communication skills can be considered as a major issue that could predict teacher effectiveness in Nigerian secondary schools.

\section{Purpose of the Study}

Specifically, the purpose of this study was to:

i. identify the relationship between teachers' communication skills and teachers' effectiveness;

ii. examine the difference between the communication skills with respect to teachers' gender;

iii. determine whether teaching experience will have significant influence on teachers' communication skills.

\section{Research Hypotheses}

The following hypotheses have been generated to pilot the study.

1. There is no significant relationship between communication skills and teachers effectiveness.

2. There is no significance difference between communication skills of male and female teachers and their effectiveness.

3. Teachers' teaching experience will not significantly influence their' communication skills and effectiveness.

\section{Methodology}

The study adopted the descriptive research of the survey type. The research population consists of all primary and secondary schools in Ekiti State, Nigeria. The sample consists of 330 respondents which comprises 30 principals as supervisors to rate the teachers on effectiveness and 300 students to rate their teachers on communication skills because of the direct contact that they have with their teachers. These respondents were chosen from 30 secondary schools spread across the state's three senatorial districts. The sample was chosen using simple random sampling techniques.

Two self-designed questionnaires were used for the study. These are titled "Communication Skills Questionnaire" (CSQ) and "Teacher Effectiveness Questionnaire" (TEQ). Communication Skills Questionnaire consisted two sections. Section A consists personal information. Personal information on the instruments required to know whether the moderating variables such as gender and years of experience have direct influence on the teachers to be rated. Section B consisted of ten questions that elicited data on communication abilities. The second instrument (TEQ) is divided into two parts: $\mathrm{A}$ and $\mathrm{B}$. The schools' and respondents' backgrounds are presented in Section A. Section B has ten questions about how to evaluate a teacher's efficacy. Experts from Ekiti State University's Department of Educational Management, Test and Measurement and Evaluation in Ado-Ekiti, Nigeria, validated copies of the instruments.

The instruments' reliability was determined using the test-retest approach, whereas the reliability coefficients of 0.78 and 0.73 were determined using Pearson's Product Moment Correlation. The test-retest method of reliability was used to determine the instrument's stability and consistency in measuring what it claims to measure. Pearson Product Moment Correlation, t-test, and ANOVA were used to examine the data. The significance of the three hypotheses was assessed at the 0.05 threshold of significance.

\section{Results}

The results of the study were presented as follows:

Hypothesis 1: There is no significant relationship between communication skills and teacher effectiveness.

Table 1. Communication skills and teachers' effectiveness

\begin{tabular}{|c|c|c|c|c|c|}
\hline Variation & $\mathbf{N}$ & Mean & SD & $\mathbf{r}_{\text {cal }}$ & $\mathbf{r}_{\text {tab }}$ \\
\hline $\begin{array}{l}\text { Communication } \\
\text { skills }\end{array}$ & 330 & 10.18 & 3.13 & \multirow{2}{*}{$0.527 *$} & \multirow{2}{*}{0.201} \\
\hline $\begin{array}{c}\text { Teacher } \\
\text { effectiveness }\end{array}$ & 330 & 54.06 & 18.07 & & \\
\hline
\end{tabular}

$* \mathrm{P}<0.05$

Table 1 showed that there was a significant relationship between communication skills and teachers effectiveness. The $r_{\text {cal }}(0.527)$ was greater than $r_{\text {tab }}(0.201)$ at 0.05 level of significance, the hypothesis was rejected. This implies that there is a significant relationship between communication skills and teacher effectiveness in Ekiti.

Hypothesis 2: There is no significant difference between communication skills of male and female and teacher effectiveness.

Table 2. t-test Analysis of male and female communication skills and teachers effectiveness

\begin{tabular}{|c|c|c|c|c|c|c|}
\hline Variation & $\mathbf{N}$ & Mean & SD & Df & t-cal & t-tab \\
\hline Male & 129 & 21.00 & 1.438 & \multirow{2}{*}{96} & \multirow{2}{*}{$1.753^{*}$} & 0.01 \\
\hline Female & 201 & 19.71 & 3.672 & & & \\
\hline
\end{tabular}

$* \mathrm{P}<0.05$

Table 2 presented that there was significant difference between the communication skills of male and female teachers. The $\mathrm{t}_{\mathrm{cal}}$ value $1.753^{*}$ was greater than $\mathrm{t}$-tab $(0.01)$ at 0.05 level of significance. Hence, the null hypothesis was rejected. This implies that sex of teachers has significant differences on their communication skills. The 
mean scores implies that male teachers' communication skills differ from the female communication skills. Male teachers $(\mathrm{x}=21.00)$ communication skills were higher than female teacher $(x=19.71)$ communication skills. This implies that female differs to male counterpart in terms of communication skills. Males have better communication skills than female. Therefore, female requires better communication skills.

Hypothesis 3: The teaching experience of teacher will not significantly influence their communication skills and effectiveness.

Table 3. Analysis of Variance (ANOVA) for the influence of teachers' teaching experience on the communication Skills and teacher effectiveness

\begin{tabular}{|c|c|c|c|c|c|}
\hline Source & SS & Df & MS & $\mathbf{f}_{\text {cal }}$ & $\mathrm{f}_{\text {tab }}$ \\
\cline { 1 - 4 } $\begin{array}{c}\text { Between } \\
\text { Groups }\end{array}$ & 13.446 & 1 & 13.446 & & \\
\cline { 1 - 4 } $\begin{array}{c}\text { Within } \\
\text { Groups }\end{array}$ & 1115.554 & 298 & 11.363 & \multirow{2}{*}{1.185} & .280 \\
\cline { 1 - 4 } Total & & 299 & & & \\
\hline
\end{tabular}

$\mathrm{P}<0.05$ (not significant)

Table 3 indicated the influence of teachers' teaching experience on their communication skills. The result obtained from the analysis shows that $f_{\text {cal }}(1.185)$ and f-table $(0.280)$. This was not significant at 0.05 level of significance, because the f-cal (1.185) was greater than f-table (0.280). Therefore, the null hypothesis was accepted. This implies that teachers' experience had no significant influence on their communication skills and effectiveness. This indicates that experienced and inexperienced teachers require better communication skills.

\section{Discussion}

It is impossible to overstate the link between effective communication and teacher effectiveness. Communication skills and teacher effectiveness were found to have a significant relationship in the study. Teachers need clear communication skills for better dissemination of contents taught, building cordial relationship between teachers and students and comprehension of subject matter during teaching-learning situation. Also, [19] supported the view that the better your communication skills, the more you perform designated tasks effectively. When there is a free flow of communication between the teachers and students, between the principal and teachers, between the teachers and colleagues, productivity will be enhanced. This finding supported the finding of [1] that good communication skills of teacher are the basic need of academic success of students, and professional success of life.

The study reiterates the difference between communication skills of male and female. The study reveals that males have better communication skill than females. The finding supported [12] that male and female have different communication purposes. He notes that they place greater value on their end goal and their independence. This finding corroborated the findings of [9] that the differences may be attributed to psychological and cultural differences.

The finding also revealed that teachers' working experience had no significant influence on communication skills. Both experienced teachers and teachers without experience require better communication skills. The findings support that of [16] that communication is a unceasing process of learning and mastering of skills. Teachers can improve on their communication skills by asking to observe classroom teaching practices and thereafter give feedback.

\section{Conclusion}

It was concluded that communication skills of a teacher have a lot to do with the effectiveness of teachers. Communication skills had significant contribution to teacher effectiveness. However, factor of sex made a difference in teacher effectiveness while working experience had no influence on teacher effectiveness.

\section{Recommendations}

Based on the findings, it was recommended that teachers should be made to understand that effective use of good communication skills during teaching-learning process is expedient. Teachers should improve on their own speech and gesture to ensure that their presentation is clear and logical. They should continuously enhance their skills of communication in order to improve on the teaching-learning process. The issue of disparity between male and female teachers in terms of effectiveness should be addressed. Adequate considerations must be given to both the teachers with experience and teachers without experience in terms of improving their effectiveness.

\section{REFERENCES}

[1] K. Alamgir, K. Salahuddin, Z. Syed, K. Manzoor. Communication skills of a teacher and it role in the development of the students' academic success. Journal of Education and Practice, Vol. 8, No. 1, pp. 18-21, 2017.

[2] J. Bella. Teacher effectiveness and professional competency among Higher Secondary School Teachers in Kottayam District, Kerala. 2013. Doi:http://hdi.handle.net/ $10603 / 8678$

[3] S.A. Dada. The principles of effective public speaking. Ibadan; Emman Publications. 2004.

[4] L. Darling-Hammand. Evaluating teacher effectiveness. How teacher performance assessments can measure and 
improve teaching. Center for American progress. 2010.

[5] S. Freddie. What are the benefits of communication skills to teacher. 2018. https://work.chron.com>benefits-communic ation

[6] W.K. Hoy, C.G. Miskel. Communication in schools. Educational Administration Theory, Research and Practice. $9^{\text {th }}$ Ed. New York: McGraw-Hill.

[7] V. Kareva. The Influence of classroom communication on student commitment to the university. European Scientific Journal, Vol. 7, No. 26, pp. 90-104, nd.

[8] A. L. Kiadese. An assessment of the teaching effectiveness of prevocational subjects teachers in Ogun State, Nigeria. International Journal of Vocational and Technical Education, Vol. 3, No.1, pp. 5-8, 2011.

[9] S.C. Nnamani, O.A. Oyibe. Teachers' gender and academic achievement of secondary school students in social sudies in Abakaliki, Nigeria. International Journal of Scientific Research and Education, Vol. 5, No. 8, 2016. Doi: 10.18535/ijsre/v5i08.04

[10] U. Malik, D. K. Sharma. Teaching effectiveness of secondary school teachers in relation to their professional commitment. International Educational E-Journal, Vol. II, No IV, pp. 148-154, 2013.

[11] R. Mayhew. Why important for teachers to have good communication skills. 2018. https://www.theclassroom.co $\mathrm{m}$

[12] R. Moheban. Differences in male and female communication. 2021. Retrieved from $24^{\text {th }}$ June, 2021 from www.relationshipsuite.com

[13] B. U. Onyekuru, J. O. Ibegbunam. Teaching effectiveness of secondary school teachers in Emohua Local Government Area of Rivers State, Nigeria. European Scientific Journal,
Vol.9, No.28, pp. 212-226. 2013. Doi: https://doi.org/10.19044/esj.2013.v9n28pq025p

[14] J. I. Oviawe. Teachers' effectiveness as correlates of students' academic achievement in Basic Technology in Nigeria. International Journal of Academic Research in Progressive Education and Development, Vol. 5, No. 2, pp. 111-119, 2016.

[15] P. Pachaiyappan, D. Ushalaya Raj, Evaluating the teacher effectiveness of secondary and higher secondary school teachers. IOSR Journal of Research \& Method in Education, Vol. 4, No. 1, pp. 52-56, 2014. Doi: 10.6084/M9.FIGSHARE.1209022

[16] C. Reddy. Communication skills importance for teachers, students and employees. Retrieved on $24^{\text {th }}$ June, 2021 from https://wwwsspps.org/cms/lib/MN02207775/ Centricity/Shared/Staff\%20Flex\%20Day\%20Module\%20F iles/Communication\% 20Skills20Article.pdf

[17] C. K. Sotco. The Perceived importance of communication skills course among university students: The case of two universities in Tanzania. Vol. 4, No.2, pp. 1-12, 2014. Doi: 10.21083/ajote.v4i2.3064

[18] J.H. Stronge, T.J. Ward, L. Grant. What makes good teachers good? A cross analysis of the connection between teacher effectiveness and student achievement. Journal of teacher education, Vol. 62, No. 4, pp. 339-355, 2011. Doi: https://doi.org/10.1177/00224871 11404241

[19] R. Sword. Effective communication in the classroom: skills for teachers. 2020. Retrieved on $24^{\text {th }}$ June, 2021 from www.highspeedtraining.co.uk

[20] D. Umasankar, B. Pranab. Teaching effectiveness of secondary school teachers in the District of Purba Medinipur, West Bengal. IOSR Journal of Humanities and Social Science, Vol. 21, No.7, pp. 50-63, 2016. Doi: 10.9790/0837-2107075063 